doi: $10.2306 /$ scienceasia1513-1874.2012.38.301

\title{
Sol-gel template synthesis and photocatalytic behaviour of anatase titania nanoparticles
}

\author{
Vorrada Loryuenyonga $^{\mathrm{a}, \mathrm{b}, *}$, Kunmutta Angamnuaysiri ${ }^{\mathrm{a}}$, Jidlada Sukcharoenpong ${ }^{\mathrm{a}}$, Athijit Suwannasri $^{\mathrm{a}}$ \\ a Department of Materials Science and Engineering, Faculty of Engineering and Industrial Technology, \\ Silpakorn University, Nakhon Pathom 73000 Thailand \\ b National Centre of Excellence for Petroleum, Petrochemicals and Advanced Materials, \\ Chulalongkorn University, Bangkok 10330 Thailand
}

*Corresponding author, e-mail: vorrada@gmail.com, vorrada@su.ac.th

Received 4 Feb 2012

Accepted 1 May 2012

\begin{abstract}
In this study, titania nanoparticles were successfully prepared by a sol-gel template method, employing cetyltrimethylammonium bromide $(\mathrm{CTAB})$ and $\mathrm{CaCO}_{3}$ nanoparticles as templates. Titanium(IV) tetraisopropoxide and ethanol were used as a titanium precursor and alcoholic solvent, respectively. The obtained nanosized-titania was characterized by X-ray diffraction, transmission-electron microscopy, and $\mathrm{N}_{2}$ adsorption and desorption methods. The photocatalytic activity of titania was investigated from the photodegradation of methylene blue solution under UVC irradiation. The results indicated that the amount of anatase crystallites and pore characteristics were important factors influencing the degree of photocatalysis of titania nanoparticles. Highly crystalline anatase titania could be obtained through the controlled hydrolysis reaction rate and the formation of loose-packed titania nanoparticles, while high specific surface area could be achieved with a template method.
\end{abstract}

KEYWORDS: sol-gel processes, $\mathrm{TiO}_{2}$, cetyltrimethylammonium bromide, $\mathrm{CaCO}_{3}, \mathrm{BET}$

\section{INTRODUCTION}

Recently, nanocrystalline titania $\left(\mathrm{TiO}_{2}\right)$ has attracted tremendous attentions as a promising material for a wide range of applications such as photocatalysts, dye sensitized solar cells, and sensor devices ${ }^{1-3}$. This is due to its unique and novel properties including high photocatalytic activity, high refractive index, low cost, non-toxicity, and large energy bandgap. One of the most useful aspects of titania is its use as a photocatalyst for the degradation of organic pollutants. The photocatalytic activity of titania depends on its morphology, particle size and distribution, porosity, crystallinity, and crystal structures. Among three crystalline polymorphs of titania (anatase, rutile, and brookite), anatase, and unstable brookite phases usually exhibit high photocatalytic activities, while rutile has the highest chemical stability ${ }^{4-8}$. As a result, wellstructured anatase titania with high specific surface area favours photocatalytic activity.

The most common technique used to synthesize mesoporous and nanocrystalline titania is the solgel method, in which titania nanoparticles are prepared by hydrolysis and polycondensation reactions of titanium precursors such as titanium alkoxides. The properties of the synthesized nanoparticles can be tailored through processing parameters such as $\mathrm{pH}$, reaction temperature, catalysts, concentration and precursor molar ratio. The main factors influencing the degradation of organic materials with titania photocatalysts follow the following orders of significance: type of stabilizer $>$ type of solvent $>$ calcination temperature ${ }^{9}$. In addition, many studies ${ }^{10,11}$ have also been focused onto the controllable hydrolysis rate of titanium alkoxide. This is because high hydrolysis rate may cause uncontrolled precipitation and the formation of rutile phase, resulting in poor photocatalytic activity ${ }^{12}$. In general, the alkoxide hydrolyses quickly in water, and thus alcohol is often used as a solubilizing agent to slow down the reaction and to provide a homogeneous environment for particle growth ${ }^{13}$.

In the past decades, a number of routes have been developed to explore the preparation of mesoporous titania nanostructures with hierarchical morphologies and high specific surface areas. One of the most promising and simple methods for synthesizing such titania nanostructures is the template method. Using core template method and sol-gel process, coreshell structures are obtained. The subsequent removal of the templates by either heat treatment or solvent extraction, then, yields template-directed and 
Table 1 Anatase content, crystallite size, specific surface area, pore volume and mean particle size of synthesized titania nanoparticles prepared by sol-gel method.

\begin{tabular}{|c|c|c|c|c|c|c|c|c|c|c|}
\hline \multirow[t]{2}{*}{ Samples } & \multirow{2}{*}{$\begin{array}{l}\text { TIP } \\
(\mathrm{ml})\end{array}$} & \multirow{2}{*}{$\begin{array}{c}\text { Ethanol } \\
\text { (ml) }\end{array}$} & \multirow{2}{*}{$\begin{array}{l}\mathrm{HCl} \\
(\mathrm{ml})\end{array}$} & \multirow{2}{*}{$\begin{array}{l}\mathrm{H}_{2} \mathrm{O} \\
(\mathrm{ml})\end{array}$} & \multirow{2}{*}{$\begin{array}{c}\text { Specific surface } \\
\text { area }\left(\mathrm{m}^{2} / \mathrm{g}\right)\end{array}$} & \multirow{2}{*}{$\begin{array}{l}\text { Pore volume } \\
\qquad(\mathrm{cc} / \mathrm{g})\end{array}$} & \multirow{2}{*}{$\begin{array}{l}\text { Mean pore } \\
\text { size }(\mathrm{nm})\end{array}$} & \multirow{2}{*}{$\begin{array}{c}\% \\
\text { Anatase }\end{array}$} & \multicolumn{2}{|c|}{ crystallite size $(\mathrm{nm})$} \\
\hline & & & & & & & & & Anatase & Rutile \\
\hline $\mathrm{E} 1^{14}$ & 5.5 & 54.8 & 1.68 & 19 & 29 & 0.08 & 11 & 20 & 15 & 20 \\
\hline E2 & 5.5 & 54.8 & 1.68 & 3.3 & 33 & 0.11 & 14 & 70 & 24 & 31 \\
\hline E3 & 5.5 & 21.1 & 1.68 & 3.3 & 28 & 0.14 & 19 & 31 & 21 & 20 \\
\hline $\mathrm{E} 1-\mathrm{CaCO}_{3}$ & 5.5 & 54.8 & 1.68 & 19 & 265 & 1.58 & 24 & 14 & 6 & 10 \\
\hline E1-CTAB & 5.5 & 54.8 & 1.68 & 19 & 80 & 0.37 & 19 & 92 & 9 & 31 \\
\hline
\end{tabular}

meso-porous nanostructures. Various templates such as $\mathrm{CaCO}_{3}{ }^{15}$, styrene-acrylic acid copolymer ${ }^{16}$, and cetyltrimethylammonium bromide $(\mathrm{CTAB})^{17}$ have been successfully used.

Since the photocatalytic reaction is dictated by the properties of titania nanoparticles, it is significant to understand the factors affecting the sol-gel reactions. Our previous work ${ }^{14}$ has reported that the hydrolysis rate and calcination temperature had crucial effects on crystalline phases and pore characteristics of synthesized titania. High crystalline anatase phase with high photocatalytic activity was achieved at calcination temperature of $500{ }^{\circ} \mathrm{C}$. In this study, we reported the influence of precursor ratios on the properties of sol-gel derived titania nanoparticles. The preparation of mesoporous titania with $\mathrm{CaCO}_{3}$ nanoparticles or CTAB cationic surfactant as templates was also studied.

\section{METHODS}

\section{Synthesis}

In this study, titania nanoparticles were prepared by sol-gel method, employing tetraisopropoxide ( $\mathrm{Ti}\left[\mathrm{OCH}\left(\mathrm{CH}_{3}\right)_{2}\right]_{4} ; \quad$ TIP) as a starting precursor. Ethanol and water were employed as solvents, and $\mathrm{HCl}$ as an acidic catalyst. The volume ratios of precursors are listed in Table 1. E1 represents samples synthesized with large excess water in sol preparation ${ }^{14}$. In E3, the water content is equal to E2, but less amount of ethanol solvent is added.

Using a sol-gel method, TIP was first dissolved in ethanol. The mixture of distilled water and $\mathrm{HCl}$ was then added dropwise under vigorous stirring at room temperature. The mixture was further stirred for $3 \mathrm{~h}$, and the obtained gels were centrifuged, washed to remove excess reactants and catalyst, and dried at $80^{\circ} \mathrm{C}$ for $24 \mathrm{~h}$. Following the drying process in the oven, the samples were calcined at $500^{\circ} \mathrm{C}$ for $3 \mathrm{~h}$ at a heating rate of $5^{\circ} \mathrm{C} / \mathrm{min}$.

For template-assisted sol-gel preparation, commercial $\mathrm{CaCO}_{3}$ nanoparticles by precipitation method
(NPCC101, average particle size of $40 \mathrm{~nm}$ ) and cetyltrimethylammonium bromide (CTAB) were used as inorganic and organic templates, respectively. The main preparation of templated titania was similar to the procedure described above. The additional step is to add $14.41 \mathrm{~g} \mathrm{CaCO}_{3}$ into the TIP-ethanol mixture or to dissolve $1.66 \mathrm{~g} \mathrm{CTAB}$ in water at $40{ }^{\circ} \mathrm{C}$ before mixing with $\mathrm{HCl}$. The $\mathrm{CaCO}_{3}$ and $\mathrm{CTAB}$ were completely removed by dissolving $\mathrm{TiO}_{2} / \mathrm{CaCO}_{3}$ nanostructures in diluted $\mathrm{HCl}$ solution overnight after calcination, while the CTAB was subsequently burned out during calcination process.

\section{Characterization}

The morphology and size of the particles were observed by transmission electron microscopy (TEM, JEOL JEM-1230). Approximately 50 randomly selected particles from each samples were imaged from different areas. Assuming particles are spherical, diameters of each particle were measured, and particle size distribution could be estimated. X-ray diffraction (XRD) patterns were recorded on a BRUKER AXS: D8DISCOVER system using $\mathrm{Cu} \mathrm{K} \alpha$ radiation to analyse the crystal structure. The average crystallite sizes of anatase and rutile were estimated by employing Debye-Scherrer equation. The fraction of anatase phase is ${ }^{18}\left(1+I_{\mathrm{R}} / 0.8 I_{\mathrm{A}}\right)^{-1}$, where $I_{\mathrm{A}}$ and $I_{\mathrm{R}}$ are the intensity of strongest diffraction line of anatase (101) and rutile (110) phase, respectively. $\mathrm{N}_{2}$ adsorption and desorption experiments were conducted using Autosorb-1 instrument (Quantachrome, USA). The pore characteristics and specific surface area were determined using Brunauer-Emmett-Teller and BarrettJoyner-Halenda methods, respectively.

\section{Photocatalytic Test}

The photocatalytic activity of synthesized $\mathrm{TiO}_{2}$ nanoparticles was evaluated by measuring the photocatalytic degradation of methylene blue under UVC light irradiation (20 W UVC UV Tokiva lamp, $\lambda_{\max }=$ $254 \mathrm{~nm}$ ). Methylene blue is generally used for this 
purpose due to its stability under typical environmental conditions and against UV irradiation ${ }^{19,20}$. In addition, due to its molecular size, it is likely to be adsorbed in porous materials with meso-pores or macro-pores. All batch equilibrium experiments were conducted in the dark. In a typical experiment, $0.031 \mathrm{~g}$ of $\mathrm{TiO}_{2}$ nanoparticles was added to $50 \mathrm{ml}$ of $2 \times 10^{-5} \mathrm{M}$ methylene blue aqueous solutions. The suspensions were centrifuged, and the concentration of methylene blue was determined from the absorbance at $\lambda=664.5 \mathrm{~nm}$, using a UV-Vis spectrophotometer (Shimadzu UV-1800). The percentage of methylene blue degradation (MB degradation) was calculated as $\left(1-C / C_{0}\right)$, where $C_{0}$ is the initial concentration and $C$ is the concentration of methylene blue solution.

\section{RESULTS AND DISCUSSION}

XRD patterns of calcined titania nanoparticles and the corresponding data of XRD crystallite size are shown in Fig. 1 and Table 1, respectively. The results show that, for template-free synthesis (E1-E3 samples), E2 titania consists of the highest content of anatase and the largest anatase and rutile crystallites. Based on previous work $^{18,21}$, the rate of hydrolysis reaction increases with increasing water content, and as a result, the fast hydrolysis reaction in E1 samples would produce fine particles. However, these particles are likely to agglomerate into larger particles. The estimation of particle size distribution by TEM analysis (Fig. 2) consistently shows a wide distribution ranging from $8 \mathrm{~nm}$ up to $100 \mathrm{~nm}$. The disagreement in the particle size by TEM and crystallite size by XRD (15-20 nm) of E1 samples indicates a significant agglomeration of the synthesized titania nanoparticles. In addition to the effects on particle size and agglomeration, the amount of anatase formation generally decreases with an increase in hydrolysis rate ${ }^{22}$. From XRD results, the phase transformation of anatase to rutile is more favourable with increasing water content $(\mathrm{E} 1>\mathrm{E} 2)$. A small amount of ethanol in E3 samples, however, is likely to suppress the hydrolysis reaction, resulting in smaller particles and less anatase phase, compared to E2 samples.

For CTAB-templated titania, it is evident that most of the nanoparticles are more loosely-packed with increased pore volume (Fig. 2 and Table 1). The XRD pattern (Fig. 1) reveals that the synthesized titania is composed of anatase as the predominant phase with the presence of small amounts of rutile and brookite crystallites. The fraction of anatase phase is about $92 \%$, according to the equation above. The result illustrates that CTAB template not only induces

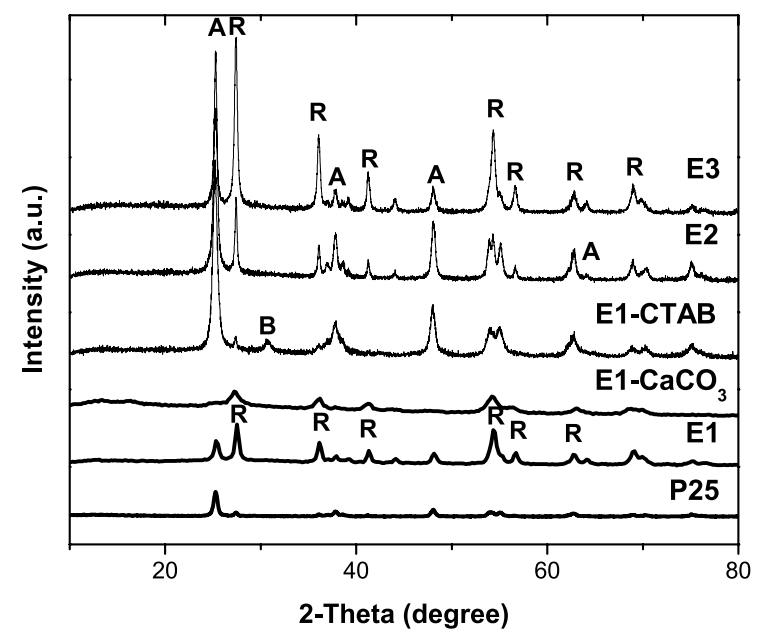

Fig. 1 XRD patterns of E1 ${ }^{14}$, E2, E3, E1-CTAB, and E1$\mathrm{CaCO}_{3}$ titania nanoparticles, compared to commercial P25 titania.

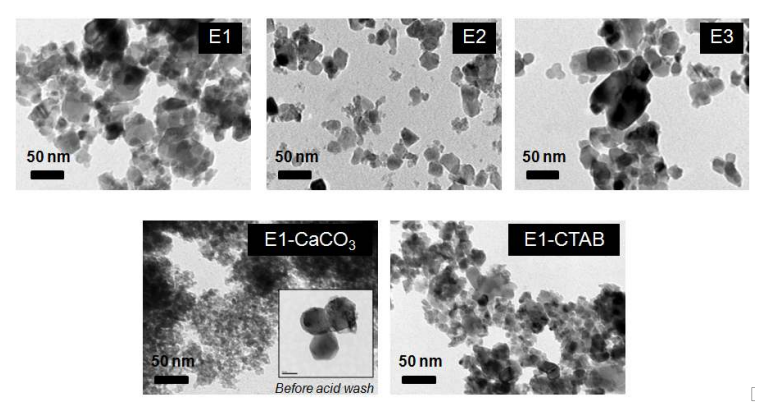

Fig. 2 TEM images of E1 ${ }^{14}$, E2, E3, E1-CTAB, and E1$\mathrm{CaCO}_{3}$ titania nanoparticles (scale bar: $50 \mathrm{~nm}$ ).

the formation of small and uniform anatase crystallites but also generates crystalline brookite. In general, the anatase-to-rutile phase transformation depends on several factors including the size of anatase crystallites, the existence of brookite phase, and the packing of titania nanocrystals ${ }^{23-26}$. It is expected that the loose packing here has a predominant influence, and therefore inhibits the transformation from anatase to rutile phases. An increase in anatase content upon the addition of CTAB surfactant is in agreement with previous work ${ }^{27,28}$.

With $\mathrm{CaCO}_{3}$ as a template $\left(\mathrm{E} 1-\mathrm{CaCO}_{3}\right)$, on the other hand, the related XRD pattern shows very broad peaks of rutile as well as weak peaks of anatase (14\%) (Fig. 1). In contrast to CTAB template, the existence of $\mathrm{CaCO}_{3}$ nanoparticles during the calcination could act as a lot of nucleating sites for the rutile formation due to the existence of defects and vacancies. As a 
result, rutile transformation was kinetically promoted, and high percentage of rutile phase was obtained. This observation is similar to the studies on the anataserutile phase transformation in the presence of various oxides as nucleating agents ${ }^{29,30}$. In general, $\mathrm{CaCO}_{3}$ nanoparticles, as a structure-directing agent, play an important role in the formation of the hollow or porous structure. The TEM image of $\mathrm{E} 1-\mathrm{CaCO}_{3}$ sample is shown in Fig. 2. The inset of the TEM image shows $\mathrm{TiO}_{2} / \mathrm{CaCO}_{3}$ nanoparticles before $\mathrm{HCl}$ acid wash. The spherical core-shell nanostructures have diameters in the range of $85-100 \mathrm{~nm}$. After the removal of $\mathrm{CaCO}_{3}$ template, the image reveals that titania nanoparticles are actually assembled from nanocrystal subunits. This observation is consistent with the value of crystallite size $(\sim 10 \mathrm{~nm})$, calculated from (110) rutile reflection peak using Scherrer equation.

Fig. 3 and Fig. 4 show the nitrogen adsorptiondesorption isotherms and the pore size distributions, respectively. The template-free titania nanoparticles calcined at $500{ }^{\circ} \mathrm{C}$ exhibits a type IV adsorption isotherm, which is a characteristic of mesoporous materials. A slight increase in adsorption between $P / P_{0}=0.95$ and 1.00 indicates that all of the calcined nanoparticles exhibit a small amount of macroporosity, which can be attributed to $\mathrm{N}_{2}$ adsorption between nanoparticles. While E1 and E2 samples show monomodal pore size distribution, the pore size distribution of E3 samples tends to be bimodal with larger mean pore size. Although less water content, the ethanol content in E3 samples was very low. A decrease in ethanol then accelerates the gelation process, causing uncontrolled pore size distribution. The specific surface areas of E1, E2, and E3 samples are in the range of $28-33 \mathrm{~m}^{2} / \mathrm{g}$.

For CTAB-templated samples (E1-CTAB), specific surface area and an average pore diameter are approximately $80 \mathrm{~m}^{2} / \mathrm{g}$ and $19 \mathrm{~nm}$, respectively (Table 1). The adsorption and desorption isotherm shows a hysteresis loop over a wide range of relative pressure due to the presence of some micro- and macro-pores (Fig. 4). Based on previous work, CTAB may play a crucial role in preventing the condensation reaction and to effectively control the morphology of sol-gel derived nanoparticles ${ }^{31,32}$. The isotherm of $\mathrm{E} 1-\mathrm{CaCO}_{3}$, on the other hand, shows a typical type-III pattern, which describes an adsorption on macropores materials. The highest specific surface area of $265 \mathrm{~m}^{2} / \mathrm{g}$ was obtained in this sample with an average pore diameter of $24 \mathrm{~nm}$.

The photocatalytic property of titania nanoparticles was examined by measuring the photodegradation of methylene blue in an aqueous suspension
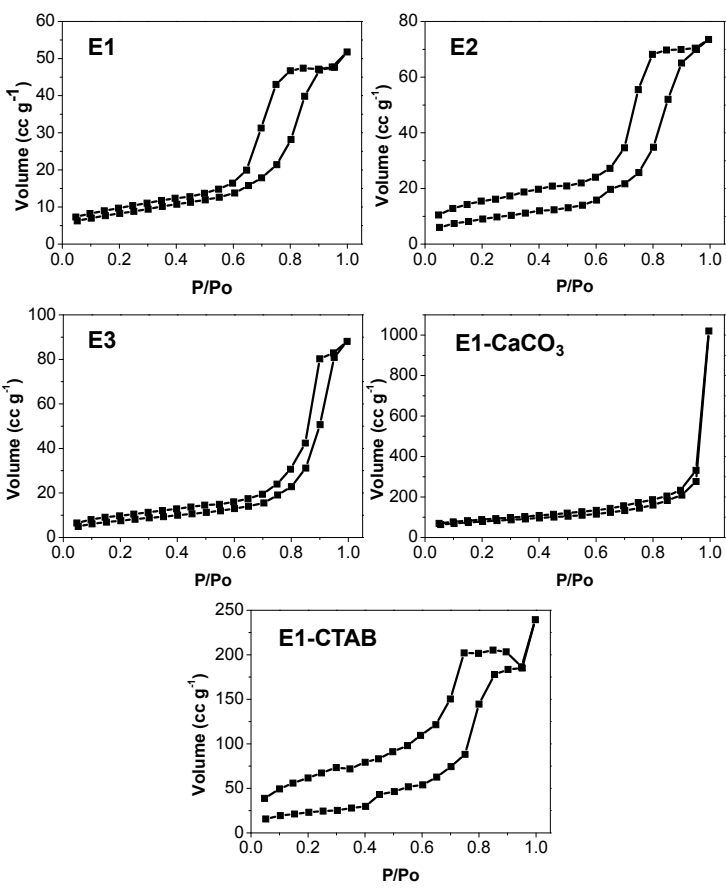

Fig. $3 \mathrm{~N}_{2}$ adsorption-desorption isotherms of $\mathrm{E} 1^{14}$, E2, E3, $\mathrm{E} 1-\mathrm{CTAB}$, and $\mathrm{E} 1-\mathrm{CaCO}_{3}$ titania nanoparticles.
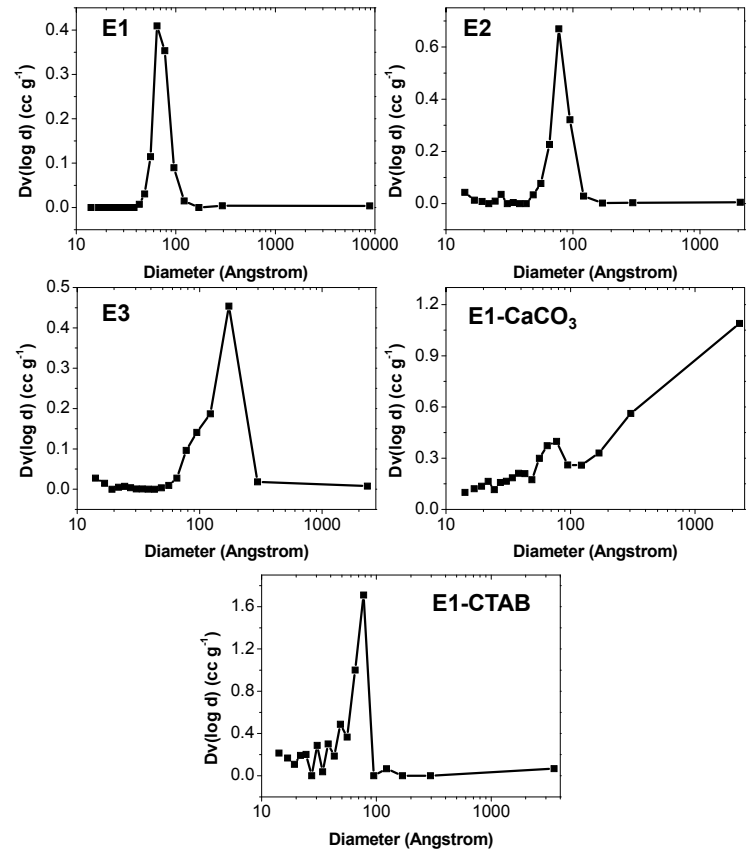

Fig. 4 Pore size distribution of E1 ${ }^{14}$, E2, E3, E1-CTAB, and $\mathrm{E} 1-\mathrm{CaCO}_{3}$ titania nanoparticles.

of titania. High anatase crystallinity typically helps to promote the separation between the photo-excited 


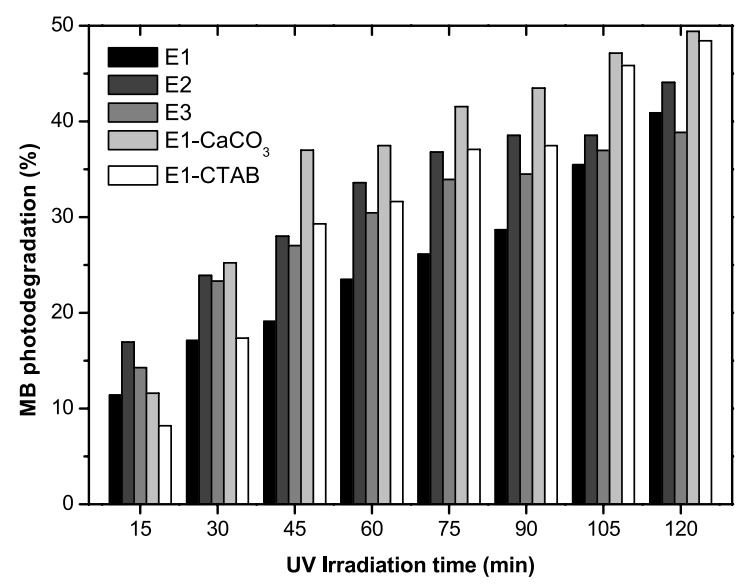

Fig. 5 The percentages of methylene blue photodegradation in different aqueous titania suspensions at different irradiation times.

electrons and holes, while high specific surface area in conjunction with suitable pore size would enhance the adsorption of organic molecules on the surface of photocatalysts ${ }^{33}$. The results show that the amount of methylene blue photodegradation increases in the sequence of $\mathrm{E} 1-\mathrm{CaCO}_{3}>\mathrm{E} 1-\mathrm{CTAB}>\mathrm{E} 2>\mathrm{E} 1>\mathrm{E} 3$. Based on the analysis of XRD patterns and pore characteristics, it can be concluded that the photocatalytic activity of titania depends on pore characteristics and the amount of anatase crystallite. Large number of micropores with sizes are comparable to the molecular size of methylene blue in E1-CTAB, however, can limit their adsorption and hence photocatalysis processes. Pure rutile titania nanoparticles do not typically exhibit photocatalytic activity of organic solution ${ }^{34}$.

\section{CONCLUSIONS}

The effects of precursor composition and templates on the crystal structure, crystallinity, crystallite size, and photocatalytic activity were investigated. The specific surface area of template-free titania nanoparticles prepared from different precursor compositions and calcined at $500{ }^{\circ} \mathrm{C}$ were not much different. However, samples with high amount of anatase crystallite were likely to have higher photocatalytic activities. High specific surface area of more than $250 \mathrm{~m}^{2} / \mathrm{g}$ titania was achieved with $\mathrm{CaCO}_{3}$ template-assisted sol-gel method. However, the presence of $\mathrm{CaCO}_{3}$ nanoparticles during calcination can act as a nucleating agent for the formation of rutile with low crystallinity and small crystallite size. High photocatalytic activities observed in $\mathrm{CaCO}_{3}$ - and CTAB-templated titania were predominantly due to appropriate pore characteristics (i.e., high specific surface) and high content of anatase crystallites, respectively.

Acknowledgements: This work is financially supported by Silpakorn University Research and Development Institute. The authors wish to thank Department of Materials Science and Engineering, Faculty of Engineering and Industrial Technology, Silpakorn University, and National Centre of Excellence for Petroleum, Petrochemicals and Advanced Materials for supporting and encouraging this investigation. We also would like to express our special and sincere gratitude to Dr Pat Sooksaen, Department of Materials Science and Engineering, Faculty of Engineering and Industrial Technology, Silpakorn University, for his valuable and constructive comments and for his important support throughout this study.

\section{REFERENCES}

1. Grätzel M (2003) Review: Dye-Sensitized Solar Cells. J Photochem Photobiol C Photochem Rev 4, 145-53.

2. Thompson TL, Yates J Jr (2006) Surface science studies of the photoactivation of $\mathrm{TiO}_{2}-\mathrm{New}$ photochemical processes. Chem Rev 106, 4428-53.

3. Pal M, Garcya Serrano J, Santiago P, Pal U (2007) Size-controlled synthesis of spherical $\mathrm{TiO}_{2}$ nanoparticles: Morphology, crystallization, and phase transition. J Phys Chem C 111, 96-102.

4. Wang G (2007) Hydrothermal synthesis and photocatalytic activity of nanocrystalline $\mathrm{TiO}_{2}$ powders in ethanol-water mixed solutions. J Mol Catal A 274, 185-91.

5. Sahni S, Reddy B, Murty B (2007) Influence parameters on the synthesis of nano-titania by sol-gel route. Mater Sci Eng A 452-453, 758-62.

6. Rao AR, Dutta V (2007) Low-temperature synthesis of $\mathrm{TiO}_{2}$ nanoparticles and preparation of $\mathrm{TiO}_{2}$ thin films by spray deposition. Sol Energ Mater Sol Cell 91 , 1075-80.

7. Park JY, Lee C, Jung KW, Jung D (2009) Structure related photocatalytic properties of $\mathrm{TiO}_{2}$. Bull Kor Chem Soc 30, 402-4.

8. Liu J, Qin W, Zuo S, Yu Y, Hao Z (2009) Solvothermalinduced phase transition and visible photocatalytic activity of nitrogen-doped titania. J Hazard Mater 163, 273-8.

9. Mastali Khan Tehrani F, Rashidzadeh M, Nemati A, Irandoukht A (2011) Factors influencing the preparation of $\mathrm{TiO}_{2}$ nanopowders from titania. Ceram Silikaty $\mathbf{5 5}, 31-5$.

10. Yang J, Mei S, Ferreira JMF (2001) Hydrothermal and synthesis of $\mathrm{TiO}_{2}$ nanopowders from tetraalkylammonium hydroxide peptided sols. Mater Sci Eng C 15, 183-5.

11. Tong T, Zhang J, Tian B, Chen F, He D (2008) Preparation and characterization of anatase $\mathrm{TiO}_{2}$ microspheres 
with porous frameworks via controlled hydrolysis of titanium alkoxide followed by hydrothermal treatment. Mater Lett 62, 2970-2.

12. Sayilkan F, Asiltürk M, Sayilkan H, Önal Y, Akarsu M, Arpaç E (2005) Characterization of $\mathrm{TiO}_{2}$ synthesized in alcohol by a sol-gel process: the effects of annealing temperature and acid catalyst. Turk J Chem 29, 697-706.

13. Spurr RA, Myers H (1957) Quantitative analysis of anatase-rutile mixture with a X-ray diffractometer. Anal Chem 29, 760-2.

14. Loryuenyong V, Angamnuaysiri K, Sukcharoenpong J, Suwannasri A (2012) Sol-gel derived mesoporous titania nanoparticles: Effects of calcination temperature and alcoholic solvent on the photocatalytic behavior. Ceram Int 38, 2233-7.

15. Bala H, Yu Y, Zhang Y (2008) Synthesis and photocatalytic oxidation properties of titania hollow spheres. Mater Lett 62, 2070-3.

16. Wang D, Song C, Liu Y, Hu Z (2006) Preparation and characterization of $\mathrm{TiO}_{2}$ hollow spheres. Mater Lett $\mathbf{6 0}$, 77-80.

17. Lee DU, Jang SR, Vittal R, Lee J, Kim KJ (2008) CTAB facilitated spherical rutile $\mathrm{TiO}_{2}$ particles and their advantages in a dye-sensitized solar cell. Sol Energ 82, 1042-8.

18. Bernards TNM, van Bommel MJ, Boonstra $\mathrm{AH}$ (1991) Hydrolysis-condensation processes of the tetraalkoxysilanes TPOS, TEOS and TMOS in some alcoholic solvents. J Non Cryst Solids 134, 1-13.

19. Yogi Ch Kojima K, Wada N, Tokumoto H, Takai T, Mizoguchi T, Tamiaki H (2008) Photocatalytic degradation of methylene blue by $\mathrm{TiO}_{2}$ film and Au particles$\mathrm{TiO}_{2}$ composite film. Thin Solid Films 516, 5881-4.

20. Jian-xiao LV, Ying Cui Guo-hong Xie Ling-yun Zhou Su-fen Wang (2011) Decoloration of methylene blue simulated wastewater using a UV- $\mathrm{H}_{2} \mathrm{O}_{2}$ combined system. $J$ Water Reuse Desalination 1, 45-51.

21. Mine E, Nagao D, Kobayashi Y, Konno M (2005) Solvent effects on particle formation in hydrolysis of tetraethyl orthosilicate. J Sol Gel Sci Tech 35, 197-201.

22. Sing KSW, Everett DH, Haul RAW, Moscow L, Pierotti RA, Rouquerol J, Siemieniewska T (1985) Reporting physisorption data for gas/solid systems with special reference to the determination of surface area and porosity. Pure Appl Chem 57, 603-19.

23. Zheng R, Meng X, Tang F (2009) Synthesis, characterization and photodegradation study of mixed-phase titania hollow submicrospheres with rough surface. Appl Surf Sci 255, 5989-94.

24. Wang P, Chen D, Tang FQ (2006) Preparation of titania-coated polystyrene particles in mixed solvents by ammonia catalysis. Langmuir 22, 4832-5.

25. Zhang H, Banfield JF (1998) Thermodynamic analysis of phase stability of nanocrystalline titania. $J$ Mater Chem 9, 2073-6.

26. Hu Y, Tsai HL, Huang LC (2003) Effect of brookite phase on the anatase-rutile transition in titania nanoparticles. J Eur Ceram Soc 23, 691-6.

27. Liu GQ, Jin ZG, Liu XX, Wang T, Liu ZF (2007) Anatase $\mathrm{TiO}_{2}$ porous thin films prepared by sol-gel method using CTAB surfactant. J Sol Gel Sci Tech 41, 49-55.

28. Benkacem T, Agoudjil N (2008) Synthesis of mesoporous titania with surfactant and its characterization. Am J Appl Sci 5, 1437-41.

29. Gennari FC, Pasquevich DM (1998) Kinetics of the anatase-rutile transformation in $\mathrm{TiO}_{2}$ in the presence of $\mathrm{Fe}_{2} \mathrm{O}_{3}$. J Mater Sci 33, 1571-8.

30. Shannon RD, Pask JA (1965) Kinetics of the anataserutile transformation. J Am Ceram Soc 48, 391-8.

31. Luo S, Wang F, Shi Z, Xin F (2009) Preparation of highly active photocatalyst anatase $\mathrm{TiO}_{2}$ by mixed template method. J Sol Gel Sci Tech 52, 1-7.

32. Benkacem T, Agoudjil N (2008) Synthesis of mesoporous titania with surfactant and its characterization. Am J Appl Sci 5, 1437-41.

33. Ohtani B, Ogawa Y, Nishimoto SI (1997) Photocatalytic activity of amorphous-anatase mixture of titanium(IV) oxide particles suspended in aqueous solutions. J Phys Chem B 101, 3746-52.

34. Zheng R, Meng X, Tang F (2009) Synthesis, characterization and photodegradation study of mixed-phase titania hollow submicrospheres with rough surface. Appl Surf Sci 255, 5989-94. 